\title{
Development Durations, Colonization and Insecticide Efficacy of Leaf Mite, Oligonychus oryzae Hirst on Rice
}

\author{
V. Radhakrishnan and K. Ramaraju \\ Department of Agricultural Entomology \\ Tamil Nadu Agricultural University \\ Coimbatore 641 003, Tamil Nadu \\ India
}

\begin{abstract}
Oligonychus oryzae is an economic mite pest infesting rice crops in India and other Asian countries. This study examined the duration of development instars at $20^{\circ} \mathrm{C}$ $-35^{\circ} \mathrm{C}$, level of colonization of mites in eight commercial rice varieties viz., ADT 36, ADT 43, ADT 45, IR 50, CO 47, ASD 16, ADTRH 1 and TN 1 and assessment of efficacy of five insecticides against $\underline{O}$ oryzae during 2005 and 2006. The duration of development from egg to adult lasted $8.33 \pm 0.20$ days at $35{ }^{\circ} \mathrm{C}$. ASD 16, ADTRH 1 and CO 47 were moderately resistant to leaf mite; $A D T 45, T N 1, I R 50$ and ADT 36 were moderately susceptible; ADT 43 was the most susceptible variety. Among the chemicals tested, Abamectin 1.8 EC was found to be the most effective.
\end{abstract}

\section{INTRODUCTION}

Rice, Oryza sativa L., supplies food for nearly half of the world's population. The crop is extensively cultivated in South and South East Asian countries. Rice crop is the foundation of national stability and economic growth in many developing countries including India. In India, the average productivity of rice is 2.11 tonnes per hectare (Viraktamath and Shobha 2008).

Among the arthropod pests, insects are considered as the major pest group threatening rice production. In recent years, mites have become a greater concern to the successful cultivation of rice in India, particularly South India. Among the mites, the rice leaf mite, Oligonychus oryzae Hirst (Acari: Tetranychidae) is the predominant species. Oligonychus senegalensis Gutierrez and Etienne is the most abundant leaf mite on rice in Senegal (Etienne, 1987). Oligonychus pratensis also feeds on rice, maize, sugarcane, sorghum and wheat (Gutierrez and Etienne, 1981). Mites of the genus Oligonychus are well-known as grass-feeders (Beard and Walter, 2001).

The occurrence of O. oryzae on rice was first reported from South India by Cherian (1931). Nagarajan (1957) reported this mite as a serious pest, causing considerable loss, but reported its incidence as sporadic. Occurrence, damage, bio-ecology, varietal screening and management aspects of this mite have been studied in India (Cherian, 1938; Misra and Israel, 1968; Rai et al., 1977 and Karuppuchamy et al., 1987). Mukherjee et al.,(1989) studied the relative incidence of $O$. oryzae on nine varieties of paddy and Karuppuchamy et al., (1987) also reported the susceptibility of IR lines against $O$. oryzae. 
In India, severe outbreak of this mite had been reported in Karnataka State (Rai et al., 1977) and considerable yield loss was reported by Swamiappan (1986). Besides paddy, several weeds, in and around paddy fields, Panicum coloratum L., P. crusgalli (Cherian, 1938; Nagarajan, 1957), Cyanodon dactylon (L.) (Misra and Israel, 1968) and Echinochloa colona (L.) have been reported as alternate hosts for O. oryzae.

The occurrence of rice leaf mite appears to have increased greatly in India, particularly in Tamil Nadu, when compared to insect pests in rice. In the absence of rain, prolonged dry climatic conditions provide a congenial atmosphere for the multiplication of mites. Even though studies were conducted in different parts of India, no detailed study was conducted on commercially cultivated varieties in Tamil Nadu. Hence, the objectives of this study were to examine the duration of development instars, level of colonization of mites in eight commercial rice varieties and assessment of efficacy of five acaricides against $O$. oryzae.

\section{MATERIALS AND METHODS}

\section{Duration of development instars of $O$. oryzae}

An experiment was conducted at five different temperatures $\left(20,25,28,30\right.$ and $\left.35^{\circ} \mathrm{C}\right)$ and $85 \%$ Relative Humidity, to study the biology of 0 . oryzae on the ADT 43 (ADT = Aduthurai) rice variety at the Acarology laboratory of Tamil Nadu Agricultural University (TNAU). Uninfested rice leaves, (25 day old plants) were cut into $4 \mathrm{~cm}$ length pieces and five such pieces were placed over filter paper kept on moist cotton in a petri dish $(50 \mathrm{~mm}$ diameter). Five gravid females were released in each petri dish for egg laying and as soon as enough eggs were laid all females were removed. Thirty unhatched eggs were maintained in each dish for observation. There were five replications. Observations were made every 6 hours until all mites reached adulthood. Observations on per cent egg hatching, developmental periods and adult longevity were recorded. Data were subjected to a one-way analysis of variance and LSD was employed to separate the treatment means.

\section{Varietal screening}

A field experiment was conducted to study the relationship between the $O$. oryzae and relative tolerance (varietal susceptibility) of different commercially grown rice varieties viz., ADT 36, ADT 43, ADT 45, IR 50, CO 47, ASD 16, TN 1 and ADTRH 1 from June 2006 to September 2006 Kharif season. The varieties were grown in $5 \mathrm{~m}$ long rows with spacing of $20 \times 20 \mathrm{~cm}$ and were replicated thrice. Five rows were maintained in each variety. The susceptible check TN 1 was maintained after every 20 rows and along the borders to act as "infester rows" (natural infestation). No pesticide was used during crop growth. The mite population was recorded in $10 \mathrm{~cm}$ leaf length from nine plants at random in each replication on 40, 50 and 60 days after transplanting (DAT). In addition, leaf damage rating was also made during the last week when almost all the plants showed drying symptoms. For the assessment of leaf damage all the leaves on the selected plants were graded based on the rating scale adopted by Archer (1987), where grade or rating $1=1-10 \%, 2=11-20 \%, 3=21$ $30 \%, 4=31-40 \%, 5=41-50 \%, 6=51-60 \%, 7=61-70 \%, 8=71-80 \%, 9=81-90 \%$ and $10=$ $91-100 \%$ (leaf area damage). The level of resistance was categorized as given in Table 1 . 
Table 1. Categorization of the level of resistance

\begin{tabular}{ccl}
\hline $\begin{array}{l}\text { Leaf damage } \\
\text { percentage }\end{array}$ & $\begin{array}{c}\text { Mean leaf damage } \\
\text { rating }\end{array}$ & Level of resistance \\
\hline $0-40$ & $1-4$ & Resistant ( R ) \\
$41-60$ & $>4-6$ & Moderately Resistant (MR) \\
$61-80$ & $>6-8$ & Moderately Susceptible (MS) \\
$>80$ & $>8$ & Susceptible (S) \\
\hline
\end{tabular}

The treatment mean values were compared using Duncan's Multiple Range Test (DMRT) (p=0.05) (Duncan, 1951).

\section{Morphological and physical studies}

Based on the field screening, varieties representing Moderately Resistant (ASD 16 and CO 47), Moderately Susceptible (TN 1) and Susceptible (ADT 43) categories were selected to study the morphological and physical characters offering resistance. The morphological characters of paddy leaves such as length and width were measured in centimeters. Thin sections of leaves were examined under a microscope and number of veins was recorded. The interveinal distance was also measured.

\section{Estimation of trichome density}

The method described by Maite et al., (1980) was followed to determine trichome density. Leaf samples were cut into $1 \mathrm{~cm}^{2}$ pieces and heated in $20 \mathrm{ml}$ of water in small glass vials for $15 \mathrm{~min}$. in an incubator set at $85^{\circ} \mathrm{C}$. The water was then poured off and $20 \mathrm{ml}$ of $96 \%$ ethyl alcohol was added. The samples were heated at $80^{\circ} \mathrm{C}$ for $20 \mathrm{~min}$. Fresh alcohol was added until all the chlorophyll was removed. Then, the leaf samples were heated at $85^{\circ} \mathrm{C}$ by adding $90 \%$ concentrated lactic acid until the leaf segments were cleared. Later, the vials were cooled and stored for observation. The number of trichomes per $\mathrm{cm}^{2}$ was counted under a compound microscope at $45 \mathrm{x}$ magnification.

\section{Efficacy of pesticides against rice mite}

Two field experiments, one each during 2005 and 2006 kharif seasons were conducted to test the efficacy of four acaricides and a botanical against $O$. oryzae. The experiments were arranged as a Randomized Complete Block Design (RCBD) with three replications and six treatments. The plot size was $5 \times 4 \mathrm{~m}$ with $20 \times 20 \mathrm{~cm}$ spacing. The acaricides viz., Dicofol

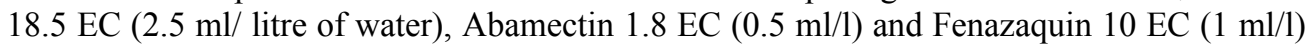
and one insecticide having acaricidal properties, profenofos $50 \mathrm{EC}(2 \mathrm{ml} / \mathrm{l})$, were compared with the botanical insecticide Econeem Plus (Azardirachtin) 1\% (2 ml/l). Water spray was given in the untreated control. The predominantly grown rice variety, ADT 43, was used and the treatments were first sprayed on the 40 day-old transplanted crop. The second spraying was given 15 days after the first spray using a hand operated high volume knap-sack sprayer. Mite populations were counted using a hand lens $(10 \mathrm{x})$. Nine hills from each plot were observed for the stages viz., egg, nymph and adult mites per $10 \mathrm{~cm}$ leaf length. Three leaves were observed randomly from each hill. The observations on the density of leaf mite were recorded based on the number of eggs, nymph and adults present on the under surface of the leaves at $0,3,7,10$ and 15 days after each spraying. From the data, per cent reduction of mite population after treatment was calculated using the Henderson and Tilton (1955) formula and the data were analyzed. Data on yield parameters were also analyzed 
statistically as per Gomez and Gomez (1984). The treatment means were compared using Duncan's Multiple Range Test (DMRT) $(\mathrm{p}=0.05)$ (Duncan, 1951).

\section{RESULTS AND DISCUSSION}

\section{Duration of development instars of $O$. oryzae}

Eggs of $O$. oryzae were minute, spherical or globular in shape and pale whitish-yellow. Eggs were deposited on the lower surface of the leaves. Freshly laid eggs were colourless or clear and later turned pale yellow. The incubation periods were significantly different among the temperatures tested. The longest incubation period was $6.3 \pm 0.52$ days at $20^{\circ} \mathrm{C}$, where, only 2.58 and 2.61 days were required at 30 and $35^{\circ} \mathrm{C}$, respectively (Table 2).

The newly hatched larva was white with four dark spots. The larvae were active for $2.3-3.3$ days prior to entering Protonymph depending on temperature (Table 2). There was a significant difference in larval development times at 20,25 and $28{ }^{\circ} \mathrm{C}$ but no significant difference was detected between 30 and $35^{\circ} \mathrm{C}$. The protonymph lasted $1.6-2.7$ days (Table 2). The development time of protonymph decreased significantly with increasing temperature. Deutonymph period (1.81 - 3.8 days) was variable with the temperatures (Table 2). Total life cycle lasted for $16.1,13.65,8.88,8.35$ and 8.33 days at 20, 25, 28, 30 and 35 ${ }^{\circ} \mathrm{C}$. The adult females were light grayish-brown with four prominent dark black spots on the dorsal side and lived for 8.33-13.15 days. Males were slightly pinkish and lived for 5.05 to 9.53 days. The quiescent stage after each moult was brief. The total life cycle from egg to adult was short at $35^{\circ} \mathrm{C}(8.33 \pm 0.20$ days) (Table 2$)$.

Table 2. Development time of Oligonychus oryzae on rice variety ADT 43 at different temperatures

\begin{tabular}{|c|c|c|c|c|c|c|}
\hline \multirow[t]{2}{*}{ Stage/Instar } & \multicolumn{5}{|c|}{ Duration of developmental stages (Days) (Mean* \pm S.D.) } & \multirow{2}{*}{$\begin{array}{c}\text { CD } \\
(0.05)\end{array}$} \\
\hline & $20^{\circ} \mathrm{C}$ & $25^{\circ} \mathrm{C}$ & $28^{\circ} \mathrm{C}$ & $30^{\circ} \mathrm{C}$ & $35^{\circ} \mathrm{C}$ & \\
\hline Egg & $6.3 \pm 0.52^{\mathrm{a}}$ & $5.7 \pm 0.5^{b}$ & $2.64 \pm 0.13^{\mathrm{d}}$ & $2.58 \pm 0.34^{\mathrm{c}}$ & $2.61 \pm 0.13^{\mathrm{c}}$ & 0.030 \\
\hline Larva & $3.3 \pm 0.22^{\mathrm{a}}$ & $2.95 \pm 0.17^{\mathrm{b}}$ & $2.45 \pm 0.23^{\mathrm{c}}$ & $2.33 \pm 0.15^{\mathrm{d}}$ & $2.31 \pm 0.14^{\mathrm{d}}$ & 0.025 \\
\hline Protc & $2.7 \pm 0.32^{\mathrm{a}}$ & $1.99 \pm 0.29^{\mathrm{b}}$ & $1.78 \pm 0.21^{\mathrm{c}}$ & $1.57 \pm 0.26^{\mathrm{d}}$ & $1.60 \pm 0.31^{\mathrm{d}}$ & 0.021 \\
\hline Deutonymph & $3.8 \pm 0.43^{\mathrm{a}}$ & $3.01 \pm 0.20^{\mathrm{b}}$ & $2.01 \pm 0.15^{\mathrm{b}}$ & $1.87 \pm 0.15^{\mathrm{d}}$ & $1.81 \pm 0.21^{\mathrm{d}}$ & 0.025 \\
\hline Tot & $16.1 \pm 1$ & 13.65 & $8.88=$ & $8.35 \pm$ & $8.33 \pm$ & 0.050 \\
\hline $\begin{array}{l}\text { Adult female } \\
\text { longevity }\end{array}$ & $13.15 \pm 1.29^{\mathrm{a}}$ & $12.82 \pm 0.33^{\mathrm{a}}$ & $8.33 \pm 0.36^{\mathrm{c}}$ & $8.75 \pm 0.21^{\mathrm{b}}$ & $8.66 \pm 0.28^{\mathrm{b}}$ & 0.049 \\
\hline $\begin{array}{l}\text { Adult male } \\
\text { longevity }\end{array}$ & $9.53 \pm 0.75^{\mathrm{a}}$ & $8.7 \pm 0.11^{\mathrm{b}}$ & $5.05 \pm 0.24^{\mathrm{d}}$ & $5.74 \pm 0.10^{c}$ & $5.79 \pm 0.06^{c}$ & 0.040 \\
\hline
\end{tabular}

The rate of development increased rapidly (35\%) between 25 and $28{ }^{\circ} \mathrm{C}$, but slowly, between 20 and $25{ }^{\circ} \mathrm{C}(15 \%)$. Moreover, approximately $39-42 \%$ of total life cycle was spent in the embryonic stage at 20 and $25{ }^{\circ} \mathrm{C}$ as compared to $30-31 \%$ at other temperatures. This finding was similar to those for Oligonychus perseae Tuttle, Baker and Abbatiello (32-42\%) at 25-30 ${ }^{\circ} \mathrm{C}$ (Aponte and McMurtry, 1997), Schizotetranychus celarius (Banks) $(44 \%)$ at $25{ }^{\circ} \mathrm{C}$ (Saito, 1979). Higher temperature is highly favourable for the multiplication of this mite. Higher temperatures are known to decrease the duration of the life cycle in several mite species (Sakunwarin et al., 2003, Tanigoshi et al., 1975). 
Development time for completion of the life cycle of $O$. oryzae decreased significantly with increasing temperature. A similar result was reported in Tetranychus truncates Ehara, where the longest life cycle of 16.1 days at $20{ }^{\circ} \mathrm{C}$ and the shortest life cycle of 8.33 days at $35{ }^{\circ} \mathrm{C}$ (Sakunwarin et al., 2003). The total development time of $O$. oryzae decreased over the temperature range of $20-35{ }^{\circ} \mathrm{C}$. Similar results were given by Haque et al., (2007) on Oligonychus coffeae (Nietner) and Sakunwarin et al., (2003) on T. truncatus. Boudreaux (1963) mentioned that the development time decreased for each developmental stage as temperature increased and was common for tetranychid mites while the most rapid development of many spider mite species occurred between 20 and $29{ }^{\circ} \mathrm{C}$ which agreed with the results of this study.

\section{Varietal screening}

Among the varieties screened, ADTRH 1, CO 47 and ASD 16 were identified as moderately resistant and ADT 43 was the most susceptible. ADT 45, TN 1, IR 50 and ADT 36 were grouped under moderately susceptible (Table 3). No variety was found resistant against $O$. oryzae. The susceptible variety ADT 43 supported a maximum population of 99/10 cm compared with 60 in moderately resistant variety ADTRH 1 . The susceptible check TN 1 was not found susceptible in this experiment. Since it recorded the damage rating of 7 , it was classified under moderately susceptible.

Table 3. Mean mite population and damage rating in different rice varieties

\begin{tabular}{lccc}
\hline Variety & Mite population*/10cm & Mean leaf damage rating & Level of resistance \\
\hline ADT 36 & $89^{\mathrm{de}}$ & 7 & MS \\
ADT 45 & $94^{\mathrm{ef}}$ & 8 & MS \\
TN 1 & $81^{\mathrm{cd}}$ & 7 & $\mathrm{MS}$ \\
CO 47 & $74^{\mathrm{bc}}$ & 5 & $\mathrm{MR}$ \\
IR 50 & $90^{\mathrm{def}}$ & 7 & $\mathrm{MS}$ \\
ASD 16 & $68^{\mathrm{ab}}$ & 5 & $\mathrm{MR}$ \\
ADTRH 1 & $60^{\mathrm{a}}$ & 5 & $\mathrm{MR}$ \\
ADT 43 & $99^{\mathrm{f}}$ & 9 & $\mathrm{~S}$ \\
\hline
\end{tabular}

$\mathrm{CD}(0.05)=4.219 ;$ SEd. $=2.029 ; \mathrm{F}$ value $=62.878$

*Means followed by the same letter are not significantly different at 0.05 level as determined by LSD.

\section{Morphological and physical studies}

Leaf length ranged from $32 \pm 0.55$ to $41 \pm 1.14 \mathrm{~cm}$ in all varieties and high in TN 1, ASD 16 followed by $\mathrm{CO} 47$. Leaf width $(9.5 \pm 0.17-11.8 \pm 0.12 \mathrm{~mm})$ and interveinal distance $(1.0 \pm 0.07-1.4 \pm 0.16 \mathrm{~mm})$ did not differ amongst varieties, there is no significant difference in interveinal distance of rice varieties. 


\section{Estimation of trichome density}

The number of hairs did differ and correlated with resistant varieties. The moderately resistant varieties viz., ASD 16 and CO 47 had $48 \pm 1.52$ and $34 \pm 0.95$ hairs respectively. The most susceptible variety, ADT 43, had the lowest number of hairs (14 \pm 0.89$)$. Number of veins was also high in ASD 16 followed by CO 47. Therefore, high hair density and vein number has positive relationship with level of resistance to spider mite attack.

No published records regarding the physical basis of resistance of paddy varieties to $O$. oryzae were found. Indeed, Mukherjee et al., (1989) found no influence of morphological and physical characters on the population of rice mites. However, for other crops and mite species, leaf thickness, hairiness and interveinal distance do play a significant role in relative abundance of mites (Santharam, 1976; Sithanantham and Velayutham, 1979) and the same results were found in this study.

\section{Efficacy of pesticides against rice mite}

\section{Eggs of O. oryzae}

Among the chemicals tested, Fenazaquin $(1 \mathrm{~mL} / \mathrm{L})$ was found to be the most effective treatment against mite eggs with a cumulative mean reduction of 98.01 and $97.95 \%$ over control after two rounds of spraying during 2005 and 2006, respectively while the reduction in other treatments ranged from $64.86-94.89 \%$ after two sprayings during 2005. A similar trend was also observed during 2006 (Table 4).

Table 4. Bio-efficacy of pesticides against Oligonychus oryzae on rice (after two sprayings)

\begin{tabular}{lcccccc}
\hline \multirow{2}{*}{ Treatments } & \multicolumn{2}{c}{$\begin{array}{c}\text { Cumulative reduction } \\
(\%)^{*}-\mathbf{2 0 0 5}\end{array}$} & \multicolumn{2}{c}{$\begin{array}{c}\text { Cumulative } \\
\text { reduction } \mathbf{( \% )} \\
\mathbf{2 0 0 6}\end{array}$} & \multicolumn{2}{c}{$\begin{array}{c}\text { Yield } \\
(\mathbf{t} / \mathbf{h a} .)\end{array}$} \\
\cline { 2 - 7 } & \multicolumn{2}{c}{ Eggs } & \multicolumn{2}{c}{ Nymph and adult } & $\mathbf{2 0 0 5}$ & $\mathbf{2 0 0 6}$ \\
\hline Dicofol 18.5 EC & $75^{\mathrm{d}}$ & $72.82^{\mathrm{d}}$ & $69.53^{\mathrm{d}}$ & $62.83^{\mathrm{d}}$ & $3.85^{\mathrm{bc}}$ & $4.01^{\mathrm{d}}$ \\
Abamectin 1.8 EC & $82.45^{\mathrm{c}}$ & $80.30^{\mathrm{c}}$ & $89.03^{\mathrm{a}}$ & $90.22^{\mathrm{a}}$ & $4.68^{\mathrm{a}}$ & $4.77^{\mathrm{b}}$ \\
Profenofos 50 EC & $94.89^{\mathrm{b}}$ & $96.05^{\mathrm{b}}$ & $80.51^{\mathrm{c}}$ & $78.71^{\mathrm{c}}$ & $4.34^{\mathrm{ab}}$ & $4.29^{\mathrm{c}}$ \\
Econeem plus (1\%) & $64.86^{\mathrm{e}}$ & $66.81^{\mathrm{d}}$ & $48.24^{\mathrm{e}}$ & $37.47^{\mathrm{e}}$ & $3.75^{\mathrm{cd}}$ & $3.70^{\mathrm{e}}$ \\
Fenazaquin 10 EC & $98.01^{\mathrm{a}}$ & $97.95^{\mathrm{a}}$ & $86.58^{\mathrm{b}}$ & $85.31^{\mathrm{b}}$ & $4.59^{\mathrm{a}}$ & $5.23^{\mathrm{a}}$ \\
Control & - & - & - & - & $3.34^{\mathrm{d}}$ & $3.25^{\mathrm{f}}$ \\
CD (0.05) & 3.924 & 3.858 & 1.858 & 1.820 & 0.060 & 0.030 \\
SEd. & 1.800 & 1.771 & 0.853 & 0.835 & 0.028 & 0.014 \\
F value & 89.96 & 97.64 & 321.74 & 531.97 & - & - \\
\hline
\end{tabular}

*Means followed by the same letter are not significantly different at 0.05 level as determined by LSD. 


\section{Nymph and adults of $O$. oryzae}

Abamectin 1.8 EC at $0.5 \mathrm{ml}$ per litre was significantly superior to all other treatments and affected cumulative population reduction of 89.03 and $90.22 \%$ over control during 2005 and 2006 seasons, respectively, after two sprayings. This was followed by Fenazaquin (85.31$86.58 \%$ ). In other treatments the per cent reduction ranged from 37.47 to 62.83 . Application of Econeem Plus was not very effective in reducing the mite population (Table 4).

Dhar et al., (2000) reported that spraying of Fenazaquin $10 \mathrm{EC}$ (Magister) at $2 \mathrm{ml} \mathrm{l}^{-1}$ and 1 $\mathrm{ml} \mathrm{l}^{-1}$; Fenpropathrin $10 \mathrm{EC}$ (Dannitol) at $1 \mathrm{ml} \mathrm{L}^{-1}$ and $0.5 \mathrm{ml} \mathrm{L}^{-1}$ and Dicofol $18.5 \mathrm{EC}$ (Colonel S) at $3 \mathrm{ml} \mathrm{L}^{-1}$ were effective against the motile stages of red spider mite, Tetranychus urticae Koch. Ramalho et al., (1986) reported that Dicofol 500 g a.i. ha ${ }^{-1}$ and abamectin $10.8 \mathrm{~g}$ a.i. ha ${ }^{-1}$ control the T. urticae efficiently. Jayachandran (2003) reported that spraying of Abamectin (Vertimec $1.8 \mathrm{EC}$ ) at 0.25 and $0.50 \mathrm{ml} \mathrm{L}^{-1}$ was effective against $T$. urticae on rose. Dinesh (2004) found that Abamectin 0.0012\% was more effective against $T$. urticae on okra.

The maximum yield was obtained from Abamectin treated plots $\left(4.68 \mathrm{t} \mathrm{ha}^{-1}\right.$; and $\left.4.77 \mathrm{tha}^{-1}\right)$ as against untreated check $\left(3.34 \mathrm{t} \mathrm{ha}^{-1}\right.$ and $\left.3.25 \mathrm{t} \mathrm{ha}^{-1}\right)$ which was 28 and $32 \%$ higher than the check during 2005 and 2006, respectively (Table 4).

\section{CONCLUSIONS}

Mean maximum temperature of $30{ }^{\circ} \mathrm{C}$ and $85 \%$ RH are highly favourable for the multiplication of rice mites under laboratory conditions at Coimbatore. The predominantly cultivated short duration rice variety ADT 43 was the most susceptible and ASD 16, CO 47 and ADTRH 1 were found moderately resistant to rice leaf mite. High hair density could provide moderate resistance to spider mite attack in moderately resistant varieties like ASD 16 and $\mathrm{CO} 47$. Abamectin $1.8 \mathrm{EC}$ at $0.5 \mathrm{ml} \mathrm{L}^{-1}$ was significantly superior to all other treatments in reducing the mite population under field conditions with increased yield. Since the incidences of mites prevail from tillering to panicle initiation stages, there is a possibility of yield reduction due to the reduced photosynthetic activity of the plants. Hence, it is suggested to apply an effective acaricide to control the population build-up under favourable conditions to prevent yield loss and to sustain productivity.

\section{REFERENCES}

Aponte, O. and McMurtry, J.A. (1997). Biology, life table and mating behavior of Oligonychus perseae (Acari: Tetranychidae). Int. J. Acarol. 23: 199-207.

Archer, T.L. (1987). Techniques for screening maize for resistance to mites. pp.178-183. In: Mihn, J.A., Wiseman, B.R. and Davis, F.M. (Eds.). Proceedings of the International symposium on methodologies for developing host plant resistance to maize insects. CIMMYT, Mexico.

Beard, J.J. and Walter, G.H. (2001). Host plant specificity in several species of generalist mite predators. Ecol. Entomol. 26: 562-570. 
Boudreaux, H.B. (1963). Biological aspects of some phytophagous mites. Annu. Rev. Entomol. 8: 137-154.

Cherian, M.C. (1931). South Indian Acarina. J. Asiat. Soc. Berg. Cal. 27(1): 11-147.

Cherian, M.C. (1938). Mites (Acarina) pests of crops in South India and methods of their control. Agric. Livestock India 8(5): 537-540.

Dhar, T., Dey, P.K. and Sarkar, P.K. (2000). Influence of abiotic factors on population build up of red spider mite, Tetranychus urticae on okra vis-avis. Evaluation of some new pesticides for their control. Pestology 24(9): 34-37.

Dinesh, K. (2004). Evaluation of abamectin $1.8 \mathrm{EC}$ and profenofos $50 \mathrm{EC}$ against two spotted spider mite and fruit borer on okra. M.Sc. Thesis, Tamil Nadu Agricultural University, Coimbatore, 160p.

Duncan, D.B. (1951). A significance test for differences between ranked treatment means in an analysis of variance. Va. J. Sci. 2: 171-189.

Etienne, J. (1987). Current entomological problems of rice cultivation in Casamance (Senegal) area. Agron Trop. Ser. Riz Rizi. Cult. Vivrieres Trop. 42: 47-60.

Gomez, K.A. and Gomez, A.A. (1984). Statistical procedures for agricultural research. Wiley International Science Publications, John Wiley and sons, New York. 680p.

Gutierrez, J. and Etienne, J. (1981). Quelques données sur les acariens Tetranychidae attaquant les plantes cultivées au Sénégal. Agron. Trop. 36: 391-394.

Haque, M., Wahab, A., Naher, N. and Afroza, B. (2007). Developmental stages of red spider mite, Oligonychus coffeae Neitner (Acari: Tetranychidae) infesting rose. Univ. J. Zool. Rajshahi. Univ. 26: 71-72.

Henderson, C.F. and Tilton, E.W. (1955). Tests with acaricides against the brown wheat mite. J. Econ. Entomol. 48:157-161.

Jayachandran, M. (2003). Evaluation of new acaricides against rose mites. Pestology 27(3): $28-30$.

Karuppuchamy, P., Veluswamy, R., Rajendran, R. and Sunderbabu, P.C. (1987). Rice mite, Oligonychus oryzae Hirst incidences on IR lines. Intern. Rice Res. Newsl. 12(2): 20.

Maite, R.K., Bidinger, F.R., Sheshu Reddy, K.V. and Davies, J.C. (1980). Nature and occurrence of trichomes in sorghum lines with resistance to the sorghum shootfly, Joint Progress Rep. Sorghum physiology-3 Sorghum Entomology -3 ICRISAT, Patancheru, India.

Misra, B.C. and Israel, P. (1968). Studies on the bionomics of the paddy mite, Oligonychus oryzae Hirst. (Acarina: Tetranychidae). Oryza 5: 32-37.

Mukherjee, A.B., Sarkar, P.K, Somchoudhury, A.K. and Roy, M. (1989). Relative incidence of Oligonychus oryzae on nine varieties of paddy and its control. Vol II. pp.53-57. In: G. P. 
Channa Basavanna G.P. and C. A. Viraktamath (Eds.), Progress in Acarology, Acarolgical society of India, Bangalore.

Nagarajan, K.R. (1957). A short note on Paratetranychus oryzae Hirst., the paddy mite. Madras Agric. J. 44: 480.

Rai, P.S., Channa Basavanna, G. P. and Nageshchandra, B. K. (1977). Oligonychus oryzae Hirst (Acarina: Tetranychidae) as pest of rice in Karnataka and its control. Acar. Newsl. 4: 3.

Ramalho, F.S., Fernando, J.M.M. and Menezes, N.J. (1986). Evaluation of acaricides against two spotted spider mite, Tetranychus urticae Koch. on cotton. Anais da Sociedade Entomologica do Brazil 15: 247-256.

Saito, Y. (1979). Comparative studies on life histories of three species of spider mites (Acarina: Tetranychidae). Appl. Entomol. Zool. 14: 83-94.

Sakunwarin, S., Chandrapatya, A. and Baker, G.T. (2003). Biology and life table of the cassava mite, Tetranychus truncatus Ehara (Acari: Tetranychidae). Syst. Appl. Acarol. 8: 13 24.

Santharam, B. (1976). Cotton. Indian Council of Agricultural Research, New Delhi, 66p.

Sithanantham, S. and Velayutham, N. (1979). Susceptability of different varieties of sugarcane to Aceria sacchari (Acari: Eriophyidae). pp.74-79. In: Contributions to Acarology in India Channa Basavanna G.P. (Ed.). Acarological Society of India, Bangalore.

Swamiappan, M. (1986). Mites attack in IR-56 in Malland, Tamil Nadu. Intern. Rice Res. Newsl. 11(4): 38.

Tanigoshi, L.K., Hoyt, S.C., Browne, R.W. and Logan, J.A. (1975). Influence of temperature on population increase of Tetranychus mcdanieli (Acarina: Tetranychidae). Ann. Entomol. Soc. Am. 68: 972-978.

Viraktamath, B.C. and Shobha R. N. (2008). Pivotal position achieved by combination of factors, Survey of Indian Agriculture, The Hindu: 22-25. 